\title{
História da educação de jovens e adultos em Portugal: o ingresso de jovens maiores de 23 anos no Ensino Superior
}

History of youth and adult education in Portugal: young adults over 23 years old in higher education

Historia de la educación para jóvenes y adultos en Portugal: adultos jovenes de más de 23 años en la educación superior

\author{
Michelle Castro Lima \\ Instituto Federal Goiano (Brasil) \\ https://orcid.org/0000-0002-3352-9184 \\ http://lattes.cnpq.br/3438503211913584 \\ michelle.lima@ifgoiano.edu.br \\ Isabel Sofia Fernandes Moio \\ Agrupamento Escolar de Pombal (Portugal) \\ https://orcid.org/0000-0001-7077-4966 \\ isabel.smoio@gmail.com \\ Cristina Maria Coimbra Vieira \\ Universidade de Coimbra (Portugal) \\ https://orcid.org/0000-0002-9814-1076 \\ vieira@fpce.uc.pt
}

\section{RESUMO}

O ingresso e a permanência dos jovens nas universidades portuguesas têm sido tema de discussão com a edição do Decreto-Lei n. ${ }^{\circ}$ 393-B/99, Decreto-Lei n. ${ }^{\circ}$ 49/2005 e Decreto-Lei n. ${ }^{\circ}$ 64/2006. A partir desses decretos, as universidades portuguesas passaram a oferecer concurso especial para o ingresso de estudantes maiores de 25 anos e, em 2005, para maiores de 23 que tenham concluído apenas o ensino primário. Diante dessa realidade, buscamos neste artigo investigar a história do acesso e permanência de Jovens e Adultos no ensino superior português. Para tal, realizamos um cruzamento de dados estatísticos dos cursos especiais da Universidade de Coimbra com a bibliografia sobre o tema, analisando a trajetória acadêmica e os impactos desse curso na formação dos jovens maiores de 23 anos que não concluíram o ensino secundário.

Palavras-Chave: Ensino Superior. Adultos. História. 


\begin{abstract}
The entry and stay of young people in Portuguese universities has been the subject of discussion with the edition of Decree-Law no. 393-B/99, Decree-Law no. 49/2005 and Decree-Law no. 64/2006. From these decrees on, the Portuguese universities started to offer special competitions for the enrollment of students over 25 years old and, in 2005, for those over 23 who have completed only primary education. Given this reality, we seek in this article to investigate the history of access and permanence of young people and adults in Portuguese higher education. To do this, we performed a statistical cross-referencing of the special courses of the University of Coimbra with the bibliography on the subject, analyzing the academic trajectory and the impacts of this course on the training of young people over 23 years old who did not finish high school.
\end{abstract}

Keywords: Higher Education. Adults. History.

\title{
RESUMEN
}

La entrada y permanencia de los jóvenes en las universidades portuguesas han sido objeto de discusión con la publicación del Decreto-Ley 393-B / 99, Decreto-Ley 49/2005 y el Decreto Ley $\mathrm{N}^{\circ}$ 64/2006. A partir de estos decretos, las universidades portuguesas han estado ofreciendo concurso especial para la admisión de los estudiantes mayores de 25 años, y en 2005, a aquellos mayores de 23 años de edad que han completado estudios primarios. Ante esta realidad, en este artículo se pretende investigar la historia de jóvenes y adultos el acceso y permanencia en la educación superior portugués. Para ello, realizamos un cruce de datos estadísticos de los cursos especiales de la Universidad de Coimbra con la bibliografía sobre el tema, analizando la trayectoria académica y los impactos de ese curso en la formación de los jóvenes mayores de 23 años que no concluyeron la enseñanza secundaria.

Palabras clave: Enseñanza Superior. Adultos. Historia. 


\section{Introdução}

Portugal ocupa um dos primeiros lugares na Europa em termos de abandono precoce de educação e formação da população juvenil. Segundo os dados relativos a 2016, 17,4\% de homens e 10,5\% de mulheres, com idades entre os 18 e os 24 anos, deixaram de estudar sem terem completado o ensino secundário. Essa Lacuna na formação fatalmente lhes impediria o acesso ao ensino superior. Contudo, o ingresso e a permanência dos jovens nas universidades portuguesas têm sido tema de discussão com a edição do Decreto-Lei 393-B/99 de 02 de outubro de 1999. A partir desse decreto, as universidades portuguesas passaram a oferecer concurso especial para o ingresso de estudantes que tivessem concluído apenas o ensino primário. A mencionada discussão se insere nas preocupações compartilhadas pelo grupo de países europeus a que Portugal pertence.

Em junho de 1999, na cidade de Bologna, foi firmado um acordo assinado por 29 países europeus. Esse acordo ficou conhecido como Declaração de Bolonha e tinha como objetivo fundamental fortalecer e fomentar a educação superior na Europa. A Declaração propôs mudanças no acesso ao ensino superior e na frequência a ele. Uma delas, que foi importante, é o reconhecimento dos saberes dos candidatos ao ensino superior e o regime especial para os alunos trabalhadores. Essas mudanças auxiliam na entrada, frequência e permanência dos adultos maiores de 23 anos nos cursos superiores, o que foi facilitado por meio da Lei de Bases do Sistema Educativo Português, cujo Artigo 12, no item 4, afirma que "O Estado deve criar as condições que garantam aos cidadãos a possibilidade de frequentar o ensino superior, de forma a impedir os efeitos discriminatórios decorrentes das desigualdades económicas e regionais ou de desvantagens sociais prévias" (PORTUGAL, 1986).

A declaração de Bolonha transformou significativamente a história do acesso ao ensino superior em Portugal. $O$ aumento no número de alunos maiores de 23 anos se manifestou claramente nas Universidades a partir de 2006. Nesse regime, tais candidatos, mesmo que não fossem titulares de habilitação de acesso ao ensino superior, ou seja, não tendo concluído o $12 .^{\circ}$ ano de escolaridade, poderiam realizar provas para avaliar as suas competências e capacidades com o objetivo de frequentarem esse nível de ensino.

Em 2006, o Decreto Lei no 64/2006, de 21 de março, atribuiu à Universidade a responsabilidade de gerir os exames especiais para maiores de 23 anos.

Análise dos dados da Direção-Geral de Estatísticas da Educação e Ciência (DGEEC) sobre o acesso desses alunos ao ensino superior constatou que, no ano de 2006, seu número cresceu. Em 1988 havia 14,5\% da população masculina maior de 18 anos matriculada no ensino superior, tendo essa porcentagem avançado para 48,9\% em 2006. Já na população feminina, a taxa de matrículas passou de 18\%, em 1988, para 61,1\% em 2006. Um dado relevante é que, até 2006, o número de mulheres matriculadas aumentou para em seguida ir diminuindo até o valor de aproximadamente $58 \%$, enquanto que, no caso dos homens, essa taxa aumentou após 2006, chegando a 52,5\%. Apesar desse descréscimo, ainda há mais mulheres matriculadas nos cursos superiores do que homens.

A partir desse contexto, apresentaremos a história do acesso ao ensino superior para os alunos maiores de 23 anos (Lei $n^{\circ}$ 49/2005), discorrendo sobre a trajetória histórica das provas específicas e a autonomia das universidades para realizá-las.

A partir do entendimento de Ludke e André (1986), a realização de uma pesquisa demanda o confronto entre dados, a partir de um problema definido que inquieta o pesquisador. Destarte, a metodologia utilizada nesta pesquisa perpassa a pesquisa histórica e compreende a leitura e análise de fontes bibliográficas, matérias jornalísticas, análise de relatórios educacionais e estatísticas sobre o acesso ao ensino superior. Enfim, não há uma única metodologia, pois o tratamento das fontes pode ser definido também pela sua própria característica. 
Metodologicamente, este trabalho contemplou o uso de diferentes fontes, dentre elas a documental, que, de acordo com Gil (2002), "vale-se de materiais que não receberam ainda um tratamento analítico, ou que ainda podem ser reelaborados de acordo com os objetivos da pesquisa. Com relação às fontes, elas são diversificadas e dispersas" (GIL, 2002, p. 45).

Buscamos os pequenos indícios na história da educação Portuguesa para compreender como se deu a criação e aplicação do Decreto-Lei que instituiu a avaliação especial para o Ensino Superior de Maiores de 23 anos. Nessa perspectiva, o método do paradigma indiciário ${ }^{1}$ pode contribuir sobremaneira para o presente trabalho, uma vez que seu apego ao detalhe revelador não deixa de estabelecer o diálogo entre a parte e o todo e salvaguarda o pesquisador de cair na armadilha da descrição positivista.

\section{História da Educação de Adultos em Portugal}

O ensino em Portugal, durante os séculos XVI e XVII, esteve sob os preceitos pedagógicos da Companhia de Jesus, pois ela criou e manteve diversos colégios em que o ensino era gratuito por todo o país. Somente no século XVIII, com a expulsão da ordem jesuíta de Portugal e com a reforma do Marquês de Pombal, deu-se a ruína desse modelo de ensino. Essa reforma atuou na estatização do ensino e, em 1759, criou as aulas régias. A partir dessas aulas, surgiu o ensino primário, que se tornou obrigatório durante a primeira república apenas na legislação, tendo sua obrigatoriedade efetivada somente durante o Estado Novo.

Na história da educação portuguesa, o ensino ficou dividido entre os poderes da Igreja e do Estado, sendo que, a partir da reforma pombalina, o Estado passou a controlar gradualmente a educação formal, divulgando os princípios de um sistema educativo gerido, coordenado e financiado pelo Estado. Porém, durante o reinado de D. Maria I, a coordenação do ensino voltou para as mãos da Igreja. Houve, portanto, diversas mudanças e reformas no ensino em Portugal, mas este artigo terá seu foco a partir do ano de 1888, quando foi projetada a criação de cursos para adultos. Durante o Estado Novo, de 1926 a 1974, havia um número elevado de quintas e famílias que viviam e trabalhavam na zona rural e, para os pais, não era interessante a formação de seus filhos no ensino liceal. Muitos deles os mantinham na escola apenas durante o ensino primário, pois deveriam trabalhar na quinta auxiliando nas tarefas e manutenção das lavouras. Em Portugal, a educação primária passou a ser relativamente obrigatória durante o Estado Novo e muitos pais acreditavam que seus filhos precisavam apenas saber ler e escrever para lidar com os negócios da família. Segundo Neves (2018), seu pai "Era um pai da velha guarda e um patrão da velha guarda. Os meus irmãos não iam estudar e iam trabalhar na terra. Tinha onde trabalhar na agricultura e comercializar tudo da agricultura." Esse relato revela um pensamento comum na sociedade portuguesa no Estado Novo. Os pais acreditavam que o melhor para os filhos era cuidar das quintas e da lavoura. Esse modo de encarar a educação resultou em elevado índice de adultos analfabetos ou com baixa escolarização no período.

Em Portugal, a educação de jovens e adultos é identificada como educação de adultos e, apesar de ser um fenômeno recente, não consiste em algo novo, já que, se considerarmos "a educação como um processo largo e multiforme que se confunde com o processo de vida de cada indivíduo, torna-se evidente que sempre existiu educação de adultos" (Canário, 2008, p. 12). Após a revolução francesa, tornou-se evidente a preocupação com a alfabetização dos adultos e a educação foi percebida como uma possibilidade de minimizar as injustiças sociais. Dessa forma, o estado francês assumiu a responsabilidade de lutar contra o analfabetismo e influenciou outros países europeus, entre eles Portugal.

\footnotetext{
${ }^{1}$ Ginzburg (1986/2004) investiga sobre o paradigma indiciário; para mais informações, consultar O queijo e os vermes.
} 
Durante o período da Monarquia Constitucional (1820-1910), teve destaque a reforma do Passos Manuel, ocorrida em 1836. O conjunto de reformas publicadas por Passos Manuel constituiu um marco na educação portuguesa. A ele, por exemplo, é atribuída uma série de ações voltadas para alavancar o ensino em Portugal em todos os seus níveis (CARVALHO, 1986). Contudo, as reformas não foram na prática efetivadas, o que é visível no alto índice de analfabetismo, que em 1850 era de $85 \%$ e, em 1900, de 75\%. Em 1950 ainda era grande, chegando a aproximadamente $45 \%$.

Diante do quadro de elevado analfabetismo com impactos na mão de obra qualificada, o Ministro da Educação Nacional, Fernando Andrade Pires de Lima, que esteve no poder durante oito anos (1947 a 1955), constatou a carência de mão de obra qualificada para responder aos avanços tecnológicos surgidos após a II Guerra Mundial.

Em Portugal o ensino primário passou a ser obrigatório em 1956 para homens (crianças ou adultos) e em 1960 para as meninas. Entretanto, o analfabetismo era um problema estrutural e diminuiu de forma lenta sem sofrer grande influência das deliberações administrativas e políticas. Assim, a preocupação com e a ideia da educação de adultos se fortaleceram após a revolução francesa e se consolidaram após a II Guerra Mundial de forma ordenada através do Estado. Foi a partir desse momento que a educação de adultos se solidificou, por meio de iniciativas de origem popular com o apoio de organizações não governamentais. $\mathrm{O}$ fato de passar a ser encarada como diretamente relacionada às questões econômicas do país fez com que se adaptasse à gestão do desenvolvimento, modificando a realidade social desses adultos não escolarizados. Dentro desse contexto, ela apareceu como uma tentativa para solucionar os problemas da sociedade moderna e foi se sustentando nos movimentos sociais como uma solução mágica para a instabilidade social existente.

As tentativas de educação de adultos, principalmente na I República, tinham um caráter eventual e apareciam relacionadas a movimentos sociais e religiosos com uma característica assistencial. Apesar da tutela do Estado, as ações voltadas para a Educação de Adultos tinham características assistenciais, educativas e doutrinárias.

Durante o Estado Novo, Portugal viveu uma ditadura conhecida por período Salazarista. Houve um desequilíbrio no campo educacional e viveu-se um momento autoritário baseado na trilogia ideológica "Deus, Pátria e Família". O Estado dava grande importância a normas, atitudes e valores. Havia uma supervalorização da pátria e de valores ligados à família patriarcal e machista. Percebemos também a adequação da oferta escolar à estrutura social característica

[...] de uma sociedade tradicional, de modo a usar o sistema escolar assente na extensão horizontal do ensino primário "curto" e na dissuasão sistemática de aspirações de mobilidade social ascendente, por via da frequência de níveis escolares não elementares - como instrumento da integração da ordem social pela conformidade de cada um com a sua condição. (SILVA, 1990, p. 17-18).

O Estado Novo manifestou a sua preocupação com a educação de adultos durante a década de 1950, quando foram lançadas algumas campanhas com a finalidade de acabar com o analfabetismo. O estado português interveio na educação com o Decreto-Lei $n^{\circ} 38.968$ e o Decreto-Lei $\mathrm{n}^{\circ} 38.969$, promulgados pelo Ministro Pires Lima. O primeiro decreto refere-se ao Plano de Educação Popular e o segundo, à Campanha Nacional de Educação de Adultos. 


\section{Campanha Nacional de Educação de Adultos (CNEA) e o plano de Educação Popular}

Em 1952, durante o Estado Novo, o governo propôs o Plano de Educação Popular e a Campanha Nacional de Educação de Adultos. O país passou por uma reestruturação econômica com a progressiva substituição da economia agrária pela implantação de indústrias. O novo modelo econômico exigiu do Estado uma reestruturação no âmbito educacional, pois, para trabalhar e desenvolver as indústrias, era necessária mão de obra qualificada.

Por outro lado, criando-se sérias dificuldades aos analfabetos no que respeita à sua admissão ao serviço de quaisquer entidades públicas ou privadas, não faria sentido que, ao mesmo tempo, se não dessem a esses indivíduos possibilidades de receber instrução em cursos devidamente organizados e gratuitos. (PORTUGAL, 1952, p. 1078).

Nesse sentido, em 27 de outubro de 1952 foi promulgado o Decreto-Lei $n^{\circ} 38.968$, que reforçava a obrigatoriedade do ensino primário elementar e criava os cursos de educação de adultos, promovendo a campanha nacional contra o analfabetismo.

Não parecendo razoável que o Estado continue a manter em funcionamento apenas cursos nocturnos, estabelece-se que os cursos possam funcionar de dia ou à noite, conforme os interesses do ensino o exigirem.

É, por esta forma, alargada a acção dos cursos, o que trará as maiores vantagens, principalmente à instrução de raparigas e mulheres analfabetas, para as quais o ensino nocturno não é, de modo algum, aconselhado nem, na maioria dos casos, possível.

Por estes motivos, e porque também importa dar aos cursos sentido formativo, atribui-se-lhes a designação mais ampla de "cursos de educação de adultos". (PORTUGAL, 1952, p. 1078).

O Decreto-Lei n ${ }^{\circ}$ 38.968, ao abordar a finalidade do Plano de Educação Popular, apresenta um retrospecto sobre a educação de adultos em Portugal:

É de justiça reconhecer que desde a instituição do ensino primário, em 1772, muitas vezes os governantes se empenharam em encontrar solução para o problema da instrução popular.

Não faltam na já longa história do ensino primário em Portugal as mais variadas providências de carácter legislativo, com as quais alguns Governos pretenderam fomentar a cultura do nosso povo.

As remodelações dos planos de ensino do ensino primário de 1870, 1878, 1884, 1901, 1911 e 1919 e muitas outras reformas sobre escola primária atestam que não foi por falta de legislação que os problemas da cultura elementar não encontraram as soluções adequadas.

Quem estudar toda essa abundante legislação e tiver presente o condicionalismo político e social do tempo compreenderá que iniciativas tantas vezes animadas do melhor espírito de bem servir o ensino não tivessem trazido à causa da educação popular os desejados benefícios. A instabilidade política e a insuficiência de recurso financeiro, por um lado, e, por outro, o estudo das questões no plano predominantemente teórico, com esquecimento das realidades, a 
descontinuidade na ação, a mudança constante de directrizes, a sucessão de leis contraditórias nos seus princípios e até nos seus pormenores, a falta, afinal, de uma firme política de ensino público explicam a falência das diversas reformas sobre ensino primário experimentadas até 1926. (Decreto-lei no 38.968, p. 67).

O governo português lutou contra o analfabetismo e, durante o Estado Novo, o maior investimento educacional não foi na alfabetização de adultos, mas sim na formação das crianças de sete a 12 anos. O Decreto-lei $n^{\circ} 38.968$ de 1952 afirmou que, para garantir a obrigatoriedade do ensino primário, se estabeleceu um mecanismo de multa para os responsáveis que não garantissem a seus dependentes o acesso a ele. Assim, para atingir o objetivo de diminuir o analfabetismo no país,

[...] houve que instituir um novo sistema de penalidades. Partiu-se do princípio de que não podem deixar de ser punidos os encarregados de educação que se não mostrem à altura das suas responsabilidades. [...] Basta que as entidades incumbidas de o promover ou realizar se compenetrem das especiais responsabilidades que lhes são atribuídas com vista à solução de um dos mais sérios problemas nacionais, como é o da extinção do analfabetismo. As multas, no caso de não serem pagas voluntariamente, passarão a ser aplicadas, em processo de transgressão, pelo tribunal judicial. Dão-se maiores possibilidades de defesa ao transgressor, mas este, no caso de ser condenado, não fugirá ao cumprimento da sentença, porque, no caso de não pagar a multa imposta, esta será convertida em prisão ou resgatada pela prestação de trabalho em obras públicas. (Decreto-lei no 38.968, p. 71).

A partir desse Decreto foi publicado outro, de no 38969, que, em seu primeiro capítulo, dispõe sobre a obrigatoriedade do ensino. Todas as crianças de sete a 12 anos completos deveriam ter acesso à instrução primária até a aprovação do exame do ensino elementar.

Além da obrigatoriedade do ensino primário, o governo estabeleceu algumas providências a fim de reforçá-la, tais como: a proibição da contratação para os quadros permanentes de menores de 18 anos que não tivessem feito o exame do ensino primário elementar; a proibição de ingresso do cidadão português em certas profissões por meio de despacho do Ministro das Corporações e Previdência Social; multa para quem violasse o determinado na lei; a exigência, para o trabalho nos serviços públicos no quadro permanente, de que as pessoas tivessem concluído a $3^{\mathrm{a}}$ classe do ensino primário; a proibição de exames de condutor de veículos automóveis aos indivíduos que não tivessem no mínimo a $3^{\text {a }}$ classe; a proibição de emigração a indivíduos entre 14 e 35 anos não aprovados no exame do ensino primário, exceto para mulheres que acompanhavam os maridos ou pessoas que exigissem cuidados. É relevante pontuar que as mulheres casadas que estavam acompanhando o marido poderiam emigrar sem o curso primário.

O Decreto $\mathrm{n}^{\mathrm{o}} 38.969$ discorre, no intervalo dos artigos 17 e 27, sobre os cursos de adultos e seu artigo 23 criou a Campanha Nacional contra o analfabetismo. O artigo 26 instituiu um Fundo Nacional de Educação de Adultos destinado às despesas da Campanha.

Os cursos de educação de adultos, destinados a adolescentes e adultos analfabetos, poderiam ser criados por iniciativa do Ministério da Educação ou por requerimento de qualquer entidade pública ou privada. Assim, em 1952, havia, por parte do governo, campanhas e legislação para extinção do analfabetismo em Portugal, que, obviamente, refletiam a visão doutrinária do Estado Novo 
O Estado Novo concede uma grande importância às questões educativas e define, desde o início, políticas que investem a escola como espaço privilegiado de doutrinação e de integração social. A defesa do valor educação contém crítica à lógica republicana e de instrução (ainda que ambos os regimes saibam que os termos não se excluem): ao reeditar esta dicotomia, o regime procura justificar a sua estratégia de redução e de simplificação das aprendizagens escolares e de reforço das componentes morais e religiosas. (NÓVOA, 1999, p. 591).

Destarte, para além dos índices de analfabetismo, o Governo do Estado Novo buscou, pela educação, fixar valores hegemônicos próprios do regime vigente. Segundo Nóvoa (1999),

O ideário educativo do salazarismo tem como referência a tradição e valores ditos imutáveis, que se impõem como dimensão totalizante das representações sociais e como discurso legitimador das decisões políticas e programáticas [...] A partir do apelo aos hábitos das famílias portuguesas, às práticas cristãs e às crenças e culturas populares, o Estado Novo reinventa uma ideologia fortemente integradora ou, dito doutro modo, apropria-se de uma determinada realidade e transforma-a em ideologia. (NÓVOA, 1999, p. 591).

Através do sistema administrativo na Campanha Nacional de Educação de Adultos, o governo aprimorou seu legado burocrático e centralizador dividindo as funções relativas à CNEA entre o Ministério da Educação Nacional e o Ministério das Corporações e Previdência Social.

A CNEA teve início no ano de 1952 com a finalidade de conclamar a população para superar os entraves do analfabetismo e para a necessidade da participação de particulares com o Estado Português na disseminação da cultura popular. Entretanto, ela se limitou ao processo de alfabetização na divulgação do conhecimento da leitura, escrita e ao oferecimento de um patamar básico de instrução para os analfabetos. Em um segundo momento, já em 1953, a campanha assumiu um cunho ideológico, difundindo "noções de educação moral, cívica, familiar e sanitária, de organização corporativa e de previdência, de agricultura e pecuária, de história pátria" (ADÃO, 1999, p. 600).

\section{A educação de adultos durante e após a revolução de 1974}

Apesar de já em 1971 ter-se criado uma estrutura central - Direção-Geral de Educação Permanente -, incumbida da condução das ações de alfabetização e de cursos de educação de adultos, a verdade é que até 25 de abril de 1974, em termos de conceptualização, essa área permanecia sem passado histórico (Melo et al., 1998). Essa situação fez com que Portugal entrasse num novo período histórico sem uma política pública de educação de adultos solidamente alicerçada, o que leva Alcoforado (2008) a considerar que se chega à segunda metade da década de 80 do século XX sem uma verdadeira capacidade para resolver os problemas de fundo no âmbito da educação de adultos, "mas, talvez ainda mais grave, sem revelarmos o talento para encontrar políticas públicas capazes e sem mostrarmos a arte de instituir uma rede com dinâmica suficiente para mobilizar vontades e recursos" (ALCOFORADO, 2008, p. 220).

Em 25 de abril de 1974, com o intuito de estabelecer a democracia, instituindo grandes transformações sociais, ocorreu a Revolução dos Cravos, a qual destituiu o regime salazarista em Portugal. Após a revolução de 1974, instaurou-se o período revolucionário conhecido como Processo Revolucionário em Curso - PREC, que se encerrou em 1976, ano da 
aprovação da Constituição Portuguesa. Esse período foi importante para a democratização do Ensino, para o qual apresentou novas propostas, já que, com a revolução, a reforma de Veiga Simão não chegou a ser implementada. Com relação à educação de Adultos,

[...] revela-se, ao longo das últimas décadas, um campo profundamente marcado por políticas educativas descontínuas. Sem uma tradição para convocar ou actualizar, em face de uma história de que sobressai o desapego das elites políticas e culturais relativamente à educação básica dos seus concidadãos, bem como a ausência de grandes instituições educativas ou de movimentos sociais com impacto na educação da população adulta, o regime democrático viria a ser confrontado com a necessidade de reinventar políticas de educação de adultos, atribuindo-lhes maior protagonismo no âmbito das políticas públicas e, especialmente, construindo um setor e uma oferta pública capazes de enfrentar uma situação socioeducativa de manifesta gravidade. Recorde-se que em meados da década de 1970 cerca de um quarto da população portuguesa era analfabeta, as taxas de escolarização entre crianças e jovens revelavam-se extremamente baixas e, não obstante os incrementos ocorridos a partir da década anterior, a população universitária era diminuta. (LIMA, 2005, p. 31).

Diante desse cenário político de democratização no país, com maior abertura para as transformações sociais, a educação de adultos assumiu outro patamar apoiando-se em políticas de educação crítica (Lima, 2008), a partir de uma mudança drástica na maneira como a educação era pensada. Assim, o Estado implementou uma parceria com a sociedade civil por meio das associações populares, proporcionando novas possibilidades de educação de adultos com intuito de promover justiça social a partir de transformações significativas na sociedade. Para Guimarães e Barros (2015), esse acordo com novas práticas estava voltado ao fomento da reflexão crítica e emancipatória.

A educação popular, impulsionada por essa cooperação, passou a beneficiar amplos setores da população em um contexto em que aproximadamente um quarto da população era analfabeta. É importante destacar que, segundo o recenseamento da população efetuado em 1970, 49,8\% da população portuguesa, com 14 ou mais anos, não possuía nem frequentava o ensino primário elementar.

Em 1976 foi redigida a Constituição da República Portuguesa pela Assembleia Constituinte eleita após as eleições gerais livres no país em 25 de abril de 1975. Ela entrou em vigor em 25 de abril de 1976 com um forte sentimento socializante. Em seu artigo 73, afirmava que:

1. Todos têm direito à educação e à cultura.

2. O Estado promoverá a democratização da educação e as condições para que a educação, realizada através da escola e de outros meios formativos, contribua para o desenvolvimento da personalidade e para o progresso da sociedade democrática e socialista.

3. O Estado promoverá a democratização da cultura, incentivando e assegurando o acesso de todos os cidadãos, em especial dos trabalhadores, à fruição e criação cultural, através de organizações populares de base, colectividades de cultura e recreio, meios de comunicação social e outros meios adequados (PORTUGAL, 1976). 
Entre outros elementos, a Constituição definiu que compete ao Estado a democratização da educação, com a dinamização de diversas modalidades educativas (formais e não formais), na busca por igualdade de oportunidades para a superação das desigualdades econômicas, sociais e culturais com a pretensão do desenvolvimento pessoal e social dos cidadãos.

Ao final da década de 70, a Lei no 3 de 10 de janeiro de 1979, intitulada "Eliminação do Analfabetismo", atribuiu ao Governo a responsabilidade de elaboração do Plano Nacional de Alfabetização e Educação de Base de Adultos - PNAEBA.

1 - Incumbe ao Estado, nos termos da Constituição, assegurar o ensino básico universal e eliminar o analfabetismo.

2 - A iniciativa do Estado deve concretizar-se pela acção conjunta dos órgãos de administração central e local, com respeito pelo princípio da descentralização administrativa.

3 - O Estado reconhece e apoia as iniciativas existentes no domínio da alfabetização e educação de base dos adultos, designadamente as de associações de educação popular, de colectividades de cultura e recreio, de cooperativas de cultura, de organizações populares de base territorial, de organizações sindicais, de comissões de trabalhadores e de organizações confessionais. (PORTUGAL, 1979, p. 35).

A referida lei compreende a alfabetização e a educação de base a partir da valorização pessoal do adulto e sua gradual inserção na vida cultural, social e política, buscando uma sociedade democrática e emancipada. Dessa forma, o processo de alfabetização foi desenvolvido por projetos de educação formal e não formal relevantes para os adultos. A partir da Lei $\mathrm{n}^{\circ} 3 / 79$, foi definido um currículo que inserisse os adultos nos vários níveis de escolarização obrigatória, exceto o ensino básico elementar.

Ao entrelaçar a educação popular com a educação de base entre 1974 e 1980, a educação de adultos assumiu caráter abrangente do direito à educação dentro das políticas públicas. Porém, apesar de os documentos caminharem para a ideia de ampliação do direito à educação, na prática essas políticas se mostraram frágeis.

Fundamentada na modernização e no controle estatal, a partir da década de 1980, houve uma retomada das normas escolares segundo o controle centralizado da educação, o que resultou na redução do campo de educação de adultos. Assim, a educação de adultos, conhecida por ensino recorrente, passou por uma progressiva formalização. Esse movimento se concretizou na Lei ${ }^{\circ} 3$ de 1979 (Eliminação do Analfabetismo), que afima ser função do Estado garantir o ensino básico universal e eliminar o analfabetismo, e que compete ao Governo:

a) elaborar o Plano Nacional de Alfabetização e Educação de Base de Adultos e promover a sua publicação e execução e colaboração com os órgãos definidos na presente lei; b) Incluir nas propostas de lei do Orçamento Geral do Estado as verbas necessárias à efectivação da presente Lei (artigo 10) (PORTUGAL, 1979, p. 37).

A Lei de Eliminação do Analfabetismo marcou a passagem da movimentação socioeducativa para o ensaio de uma organização governamental de educação de adultos com caracterísitcas social-democráticas.

A ideia apresentada pela Lei $n^{\circ} 3$ de 1979 foi interessante na medida em que elevava o potencial socioeducativo ao estabelecer uma parceria entre o estado e associações não governamentais e apresentar um sistema de educação de adultos autônomo e descentralizado. A proposta se aproveitaria da experiência de educação popular durante o PREC, porém ela 
não se concretizou. Em 1980, o Plano Nacional de Alfabetização e Educação de Base de Adultos, proposto no artigo $4^{\circ}$ da Lei $\mathrm{n}^{\mathrm{o}} 3$, foi negligenciado pelo governo e se tornou inexpressivo o apoio do Ministério da Educação à educação popular, ao associativismo e à intervenção comunitária.

Nessa perspectiva de constução de um sistema de ensino, em 1986 foi aprovada a Lei de Bases do Sistema Educativo Português - Lei $n^{\circ}$ 46/86. Tal lei organizou a educação de adultos a partir de duas propostas: o ensino recorrente e a educação extra-escolar. A primeira se caracterizou pela amplitude, com mais alunos, professores e escolas públicas envolvidos. $\mathrm{O}$ Estado, por intermédio do Ministério da Educação, na busca de promoção de igualdade de oportunidades de acesso e eficácia educativos, apropriou-se de um papel fundamental na dinamização do ensino de adultos, particularmente na concepção e no fomento de contextos e práticas educativas, como os métodos pedagógicos, acompanhamento e avaliação. Já a educação extra-escolar foi implementada por organizações não governamentais por meio de atividades integradas em projetos de intervenção comunitária. Entendida como educação de adultos liberal, também foi menos importante no que concerne aos recursos humanos e materiais dispendidos.

A Lei de Bases também limitou o campo da educação de adultos e propôs um novo entendimento de cidadania com foco na transmissão de conhecimentos de ordem disciplinar e uma gama de saberes adquiridos em contexto de sala de aula. A educação de adultos, nesse direcionamento, tinha o seu papel central no que se refere à busca por desenvolvimento e modernização do país.

\section{História do acesso à universidade para maiores de 23 anos}

Como referido anteriormente, pouco aconteceu de novo nas políticas públicas de educação e formação de adultos em Portugal até a promulgação da Lei n. ${ }^{\circ}$ 5/73, de 25 de julho - por iniciativa do então ministro Veiga Simão, e vulgarmente conhecida como a Reforma de Veiga Simão -, que "previa que o sistema educativo passasse a abranger a educação préescolar, a educação escolar e a educação permanente, organizando-se de forma integrada e global, no completo respeito (o que constituía uma absoluta novidade legislativa) pelo princípio da democratização do ensino" (Alcoforado, 2008, p. 215). De fato, coube a Veiga Simão, o último dos ministros da Educação do Estado Novo, iniciar o processo de modernização que estaria na gênese da atual organização do ensino superior português (Teodoro, Galego, Marques, 2010). Com essa Reforma visou-se à ampliação da frequência ao ensino superior, colocando a tônica no discurso meritocrático, o que mobilizou as aspirações de todos aqueles que pretendiam ter acesso a ele (Brás et al., 2012). Além disso, expandi-lo e diversificá-lo, procurando responder às necessidades de formação de recursos humanos qualificados adequados ao processo de desenvolvimento econômico, era outro dos seus desígnios (Castro et al., 2010).

O plano de expansão e de diversificação do ensino superior, aprovado pelo DecretoLei n. ${ }^{\circ}$ 402/73, de 11 de agosto, previa a criação de três novas Universidades (Universidade Nova de Lisboa, Universidade do Minho e Universidade de Aveiro), do Instituto Universitário de Évora, de Institutos Politécnicos (Covilhã, Vila Real, Faro e Leiria) e de Escolas Normais Superiores (Beja, Bragança, Castelo Branco, Funchal, Guarda, Lisboa, Ponta Delgada, Portalegre e Viseu) (Brás et al., 2012). Esse Decreto-Lei traduz a intenção de alargar a rede de instituições de ensino superior. Como tal, é legítimo considerar que a ação política de Veiga Simão "representou, inquestionavelmente, um período de mobilização de vontades e de predisposições que colocou o ensino superior no centro dos debates sobre o desenvolvimento e modernização do país" (Teodoro, Galego, Marques, 2010, p. 664). A ação política prevista por Veiga Simão representou, portanto, um período de mobilização de vontades ao apostar no ensino como fator de desenvolvimento e de modernização. 
No entanto, a revolução de abril de 1974, ao revogar a Lei $\mathrm{n}^{\circ} 5 / 73$, abandonou algumas das medidas mais relevantes de Veiga Simão (Brás et al., 2012). Nesse sentido, “o II Governo provisório encaminhou-se para a definição de uma política educacional que não dependesse da continuidade da reforma desenvolvimentista desenhada por Veiga Simão, nos últimos anos da ditadura" (Ferreira; Seixas, 2006, p. 258), o que se traduziu no claro abandono da implementação daquela Lei e na suspensão de diversas medidas que diziam respeito à expansão e à reorganização do ensino superior.

É assim que, com o fim do Estado Novo, ficou sem efeito a Lei de Veiga Simão, nunca regulamentada, tendo-se abandonado todas as opções que essa reforma anunciava e tornando necessária uma nova Lei de Bases do Sistema Educativo (Pires, 1987). Essa necessidade e a consciência social de que urgia estabilizar e clarificar a organização do sistema educativo português foram assumidas como duas fortes razões que impulsionaram a elaboração e a aprovação da Lei n. ${ }^{\circ}$ 46/86, de 14 de outubro, que passou a reger o sistema educativo em Portugal.

Embora não seja nosso intuito revisitar essa Lei em todos os seus eixos estruturantes e alterações, não seria sensato avançar sem referir que ela já previa que pessoas com idade superior a 25 anos que não estivessem habilitadas com um curso secundário, ou equivalente, pudessem fazer prova adequada de capacidade para a frequência do ensino superior (artigo 12), sendo essa prova de âmbito nacional e específica para cada curso ou grupo de cursos afins (artigo 13).

Desde então, o ensino superior tem crescido progressivamente e assumido centralidade no percurso de vida de um número cada vez maior de cidadãos, bem como nas estratégias de desenvolvimento das sociedades, dos Estados e de organismos supranacionais (como é o caso da UE) (Alves; Pires, 2009).

Entre 1986 e 2006 foram produzidas duas alterações, ambas com predominante incidência no ensino superior, no que diz respeito às políticas relativas aos ciclos de estudos superiores (cf. Figura 01).

Figura 01. Alterações à LBSE e normativas dirigidas aos maiores de 23 anos

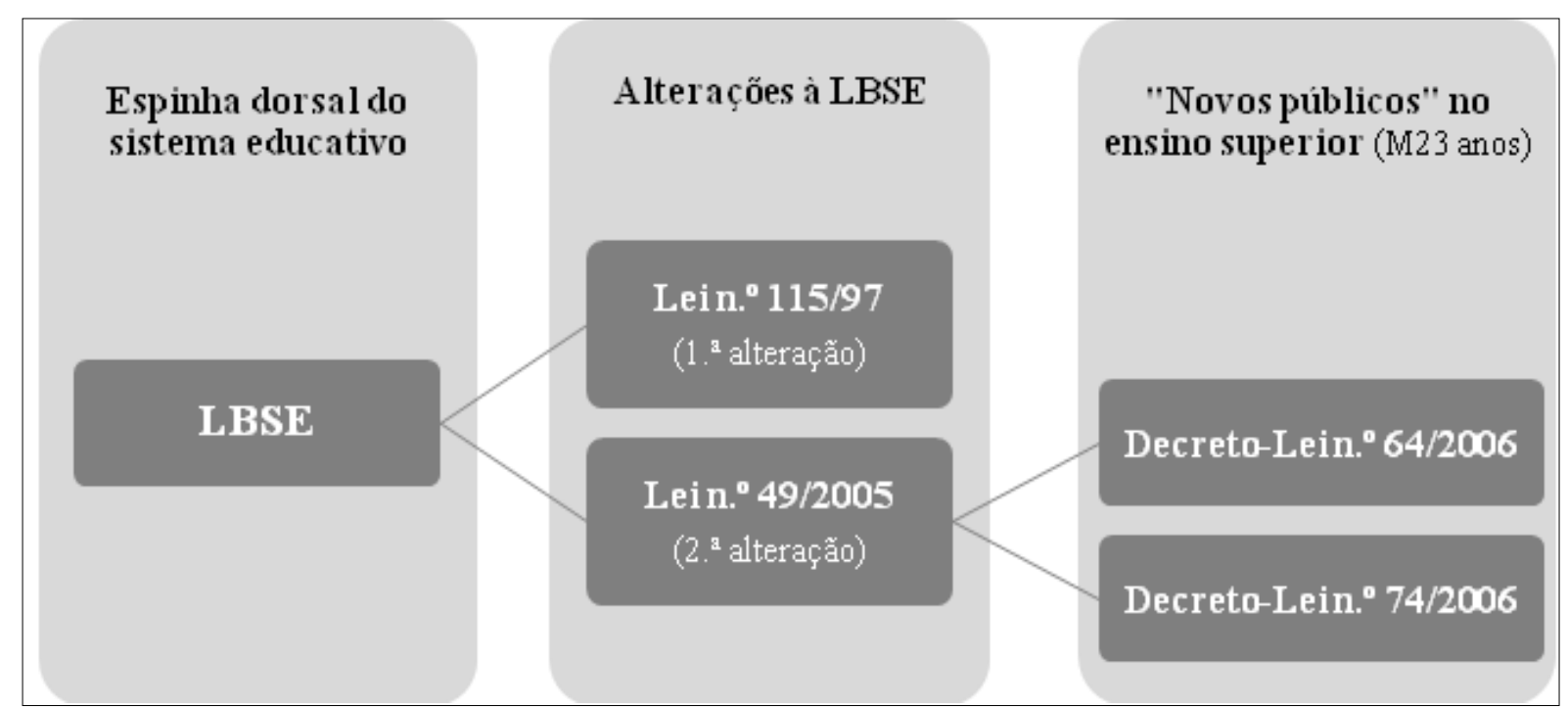

Fonte: MOIO, I. Reconhecimento de Competências no Ensino Superior: uma realidade reconhecida ou a reconhecer? Dissertação de Doutoramento (não publicada). Faculdade de Psicologia e de Ciências da Educação, Universidade de Coimbra, 2017.

A primeira alteração à LBSE foi introduzida pela Lei n. ${ }^{\circ}$ 115/97, de 19 de setembro, que, no artigo 12, refere que ao Estado compete assegurar a eliminação de restrições quantitativas de caráter global no acesso ao ensino superior, bem como promover "condições para que os cursos existentes e a criar correspondam globalmente às necessidades em quadros qualificados, às aspirações individuais e à elevação do nível educativo, cultural e científico do 
País" (pp. 5082-5083) e que têm acesso ao ensino superior "os indivíduos maiores de 25 anos que, não estando habilitados com um curso do ensino secundário ou equivalente, e não sendo titulares de um curso do ensino superior, façam prova, especialmente adequada, de capacidade para a sua frequência" (idem, p. 5083).

No entanto, será apenas quase duas décadas após a sua publicação que a LBSE viria a ser alvo de uma profunda alteração (através da Lei n. ${ }^{\circ}$ 49/2005, de 30 de agosto), com significativo impacto devido ao fato de ter estabelecido os alicerces para que fossem criadas condições tendentes à concretização do Processo de Bolonha, depois de terem sido aprovados, pelo Decreto-Lei n. ${ }^{\circ}$ 42/2005, de 22 de fevereiro, os princípios reguladores de instrumentos para a criação do Espaço Europeu do Ensino Superior (Ferreira, 2006).

As alterações contempladas na Lei n. ${ }^{\circ}$ 49/2005 - que reduziu a idade de admissão no ensino superior para 23 anos - visam a "incentivar a frequência do ensino superior, melhorar a sua qualidade e relevância, e fomentar a mobilidade e a empregabilidade dos seus diplomados, no espaço europeu" (Correia; Mesquita, 2006, p. 171). Essa alteração no regime de acesso ao ensino superior, através de concursos especiais, ao diminuir a idade de 25 para 23 anos e, sobretudo, ao conferir autonomia institucional nos processos de seleção, visa a aumentar o número de estudantes que ascende por essa via aos ciclos de estudos superiores (Castro et al., 2010).

Assim, aquela Lei foi importante por ter consagrado a criação de condições para que todos os cidadãos pudessem ter acesso à aprendizagem ao longo da vida, modificando as condições de acesso ao ensino superior para os que nele não ingressaram na idade de referência e pela via regular, atribuindo às instituições de ensino superior a responsabilidade pela sua seleção e criando condições para o reconhecimento da experiência profissional.

Foi nesse contexto que, em Portugal, no âmbito das mudanças introduzidas pelo paradigma da aprendizagem ao longo (e em todos os espaços) da vida e do Processo de Bolonha, se sentiu a necessidade de proceder à "aprovação de regras que facilitassem e flexibilizassem o ingresso e o acesso ao ensino superior, nomeadamente a estudantes que reunissem condições habilitacionais específicas" (Monteiro et al., 2015, p. 133). Assim, e no que diz respeito à participação dos adultos no ensino superior, foram adotadas medidas específicas no que concerne aos processos de ingresso. Destacam-se as iniciativas implementadas ao abrigo do Decreto-Lei n. ${ }^{\circ}$ 64/2006, de 21 de março (normativa que concedeu a cada instituição a responsabilidade pelo acesso a ciclos de estudos superiores e que regulamenta as provas adequadas para a avaliação da capacidade de adultos com idade superior a 23 anos os frequentarem - daí a designação corrente de M23 anos) e do DecretoLei n. ${ }^{\circ} 74 / 2006$, de 24 de março (que aprova o regime jurídico dos graus e diplomas do ensino superior e o novo modelo de organização dos ciclos de estudo desenvolvidos no âmbito do Processo de Bolonha, oficializando, assim, a implementação desse Processo em Portugal).

Portanto, essas normativas promovem o alargamento do acesso de "novos públicos" ao ensino superior e reconhecem a experiência profissional para efeitos de entrada e de progressão acadêmica, cuja "árvore genealógica" apresentamos na Figura 02, pois consideramos que compreender a genealogia das políticas mais recentes implica não apenas recorrer aos antecedentes mais imediatos, mas também a uma visão geral do conjunto de políticas naquilo que diz respeito aos "novos públicos" no ensino superior no último quarto do século XX. 
Figura 02. “Árvore genealógica” dos documentos normativos

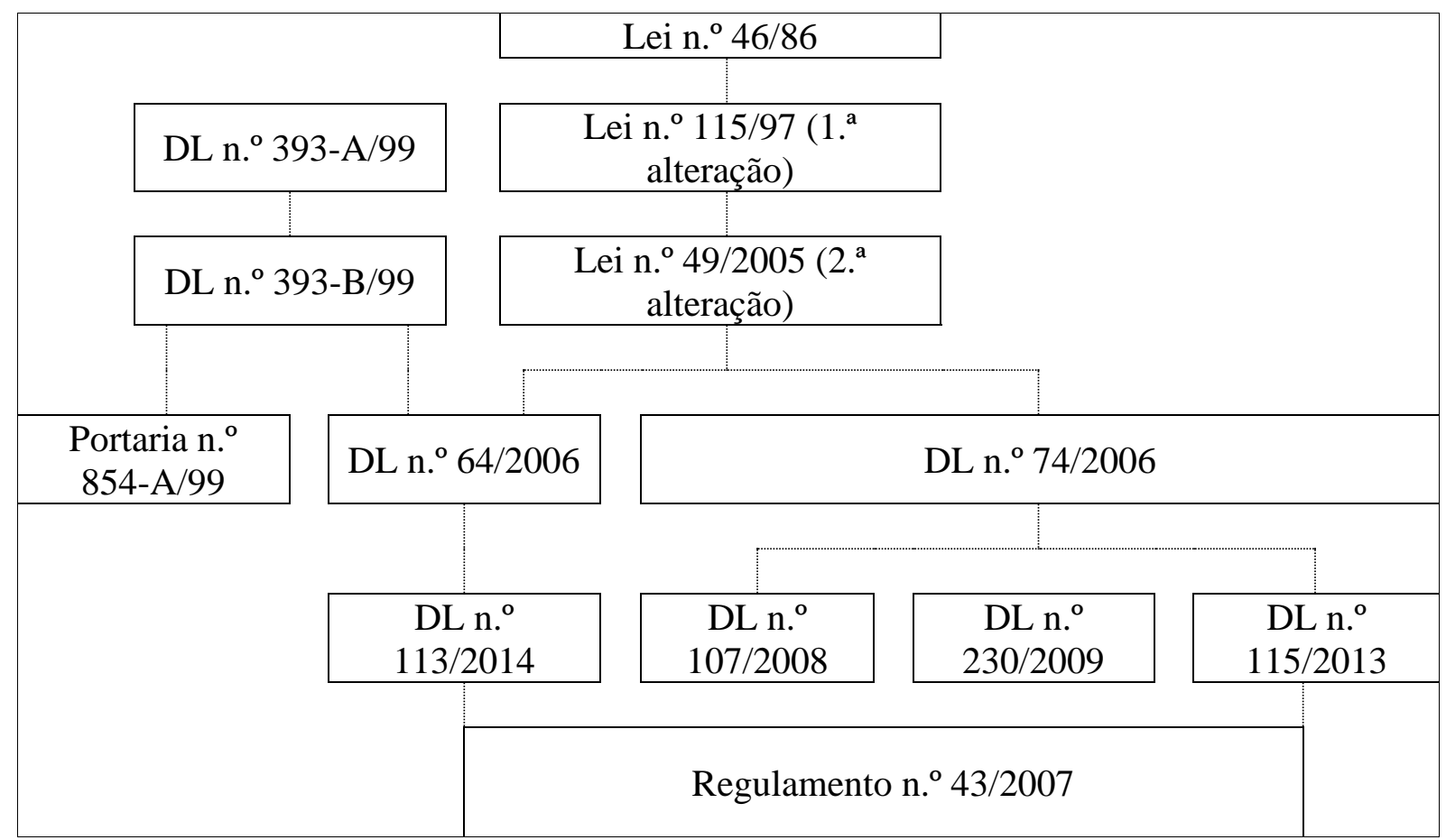

Fonte: MOIO, I. Reconhecimento de Competências no Ensino Superior: uma realidade reconhecida ou a reconhecer? Dissertação de Doutoramento (não publicada). Faculdade de Psicologia e de Ciências da Educação, Universidade de Coimbra, 2017.

Podemos considerar, portanto, que a filiação do Decreto-Lei n. ${ }^{\circ}$ 74/2006 é a Lei n. ${ }^{\circ}$ 49/2005 (segunda alteração à LBSE); já o Decreto-Lei n. ${ }^{\circ}$ 64/2006 herdou genes, por um lado, do Decreto-Lei n. ${ }^{\circ}$ 393-B/99 (que regula os concursos especiais de acesso e ingresso no ensino superior destinados a estudantes que reúnem condições habilitacionais específicas titulares do exame especial de avaliação de capacidade para acesso ao ensino superior de maiores de 25 anos, titulares de cursos superiores, pós-secundários e médios e estudantes oriundos de sistemas de ensino superior estrangeiros) e, por outro, da Lei n. ${ }^{\circ}$ 49/2005.

Verificamos também que o Decreto-Lei n. ${ }^{\circ}$ 64/2006 partilha ainda a filiação com a Portaria n. ${ }^{\circ} 854-\mathrm{A} / 99$, que aprova o regulamento dos concursos especiais de acesso ao ensino superior, a que se refere o artigo 20 do Decreto-Lei n. ${ }^{\circ} 393-B / 99^{2}$.

Dessa combinação genética surge o Regulamento n. ${ }^{\circ}$ 43/2007 - Regulamento das Provas Especialmente Adequadas destinadas a avaliar a capacidade para a frequência do ensino superior dos estudantes M23 anos na Universidade de Coimbra -, uma vez que nos termos do artigo 14 do Decreto-Lei n. ${ }^{\circ}$ 64/2006 compete ao órgão legal e estatutariamente competente de cada instituição de ensino superior elaborar e aprovar o regulamento dessas provas, previstas no parágrafo $5^{\circ}$ do artigo 12 da Lei n. ${ }^{\circ} 46 / 86$.

Podemos afirmar, portanto, que o processo dos M23 anos promove o acesso ao ensino superior em Portugal de pessoas a partir dessa idade, não titulares de habilitação de acesso ${ }^{3}$, mas que revelem competências para a sua frequência.

\footnotetext{
${ }^{2} \mathrm{O}$ artigo 25 refere, no ponto 1, que "compete ao Ministro da Educação aprovar, por portaria, o regulamento dos concursos especiais, o qual contempla: $a$ ) as regras a que obedece o requerimento de matrícula e inscrição; $b$ ) o elenco dos cursos pós-secundários abrangidos pela alínea $c$ ) do . $^{\circ} 1$ do artigo 10 , as eventuais condições adicionais a que os candidatos titulares destes cursos devem satisfazer, nomeadamente de experiência profissional, e os cursos superiores a que cada um dá acesso" e, no ponto 2, que "compete ao director-geral do Ensino Superior fixar, por seu despacho, os prazos em que devem ser praticados os actos a que se refere o presente diploma".
} 
O Decreto-Lei n. ${ }^{\circ}$ 64/2006 prevê, assim, no ponto de vista de Brás et al. (2012), a promoção da igualdade de oportunidades no acesso ao ensino superior, rompendo aquele que era considerado um elitismo histórico. Contudo, Alves e Pires (2009) alertam para a necessidade de analisar o caso do ensino superior português e, designadamente, o modo como ele tem evoluído e dado resposta (ou não) a uma das expectativas que sobre ele é habitual recair: a promoção da igualdade de oportunidades.

De acordo com Magalhães et al. (2009), a situação atual corresponde ao terceiro período da evolução das políticas portuguesas de acesso ao ensino superior, designado "mais mas diferente" ("more but different"), o que representa, na opinião dos autores, a mudança da igualdade para a equidade e da quantidade para a qualidade, bem como a diversificação da oferta formativa e a focalização em públicos mais diversos ${ }^{4}$.

Foi ainda em 2006, no quadro da massificação do ensino superior, que, com o DecretoLei n. ${ }^{\circ}$ 74/2006, começou a instituir-se o discurso da qualidade e se evidenciou uma ruptura com o paradigma do ensino, substituindo-o pelo da aprendizagem (Leite; Ramos, 2014).

Tendo em consideração que a legislação faz referência a dois aspetos distintos, mas complementares, no que concerne à valorização da experiência dos adultos no ensino superior (por um lado, o acesso e, por outro, o posicionamento avançado no ciclo de estudos através da atribuição de créditos), o enquadramento legal para tal parece traduzir, na perspectiva de Pires (2007, p. 12), "uma lógica inovadora, que consiste na valorização da experiência e da formação adquirida ou realizada fora dos contextos tradicionais de educação mediante a atribuição de créditos de natureza académica".

No entanto, a nova legislação pode ser interpretada numa perspetiva de continuidade, na medida em que, anteriormente, já era possível ascender ao ensino superior através de um exame especial (vulgarmente designado exame "ad-hoc", cf. Decreto-Lei n. ${ }^{\circ} 198 / 79$, de 29 de junho ${ }^{5}$ ). Essa não é, portanto, a primeira vez que, em Portugal, os adultos têm acesso ao ensino superior (Amorim, Azevedo, Coimbra, 2011). Por essa razão, na opinião de Pires (2007, p. 12), "o que parece emergir como inovador no ensino superior em Portugal é a possibilidade de reconhecer a experiência profissional e a formação (em sentido lato) dos candidatos, com efeitos na atribuição de créditos no âmbito do ciclo de estudos". Por isso, a mesma autora (2010) refere que, para além do enquadramento legislativo nacionalmente, é fundamental que exista vontade política em nível institucional - criando as condições e os recursos necessários - e que se envolvam os atores, promovendo novos espaços de intervenção no nível organizacional.

Segundo os dados da DGEEC, o número de alunos inscritos para as provas é maior que o número de alunos que se matriculam nos cursos superiores, conforme o gráfico a seguir:

\footnotetext{
3 Por "habilitação de acesso" entende-se a titularidade de um curso de ensino secundário ou equivalente e a realização de exames nacionais que se constituem como provas de ingresso para o curso pretendido.

${ }^{4}$ Para Magalhães et al. (2009), o primeiro período é denominado "mais é melhor" ("more is better"), tendo sido uma fase expansionista de 20 anos (entre 1974 e meados dos anos 90 do século XX), e no segundo período (1997/1998 a 2007/2008), em que "mais é um problema" ("more is a problem"), foi desencadeado um declínio do ensino superior privado, a que se seguiu (em 2003/2004) um decréscimo das inscrições no setor público.

${ }^{5}$ De acordo com o ponto 1 do Decreto-Lei n. ${ }^{\circ}$ 198/79, de 29 de junho, "desde alguns anos que, ao abrigo do Decreto-Lei n. ${ }^{\circ}$ 47587, de 10 de março de 1967, se vêm realizando, como experiência pedagógica, no quadro legal de despachos ministeriais, exames ad hoc para acesso ao ensino superior de indivíduos que, tendo mais de 25 anos de idade, não possuem a adequada habilitação escolar" (p. 1410).
} 
Figura 03. Número de estudantes inscritos no ensino superior via concurso Maiores de 23 e número de alunos inscritos e aprovados nas provas, 2006/2007-2011/2012

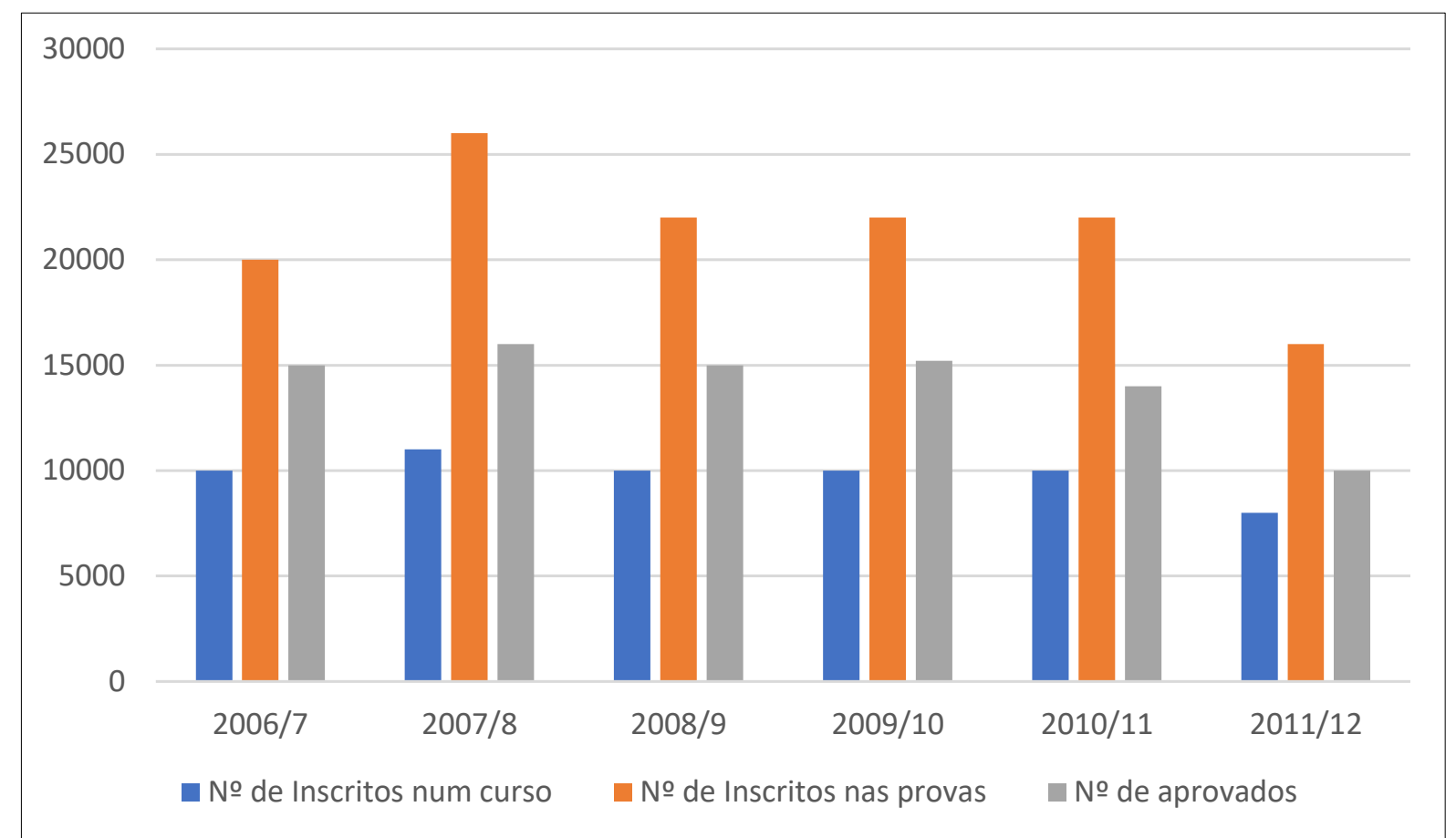

Fonte: DGEEC - Inquérito às provas especialmente adequadas destinadas a avaliar a capacidade para a frequência do ensino superior dos Maiores de 23 anos.

A proposta da Lei n. ${ }^{\circ}$ 49/2005 era garantir o acesso ao ensino superior dos adultos com mais de 23 anos que não tivessem cursado a educação básica, avaliando, para esse acesso, seus saberes e experiências de acordo com o curso escolhido. Em 2006, por meio do DecretoLei $\mathrm{n}^{\circ}$ 64, foi concedida às instituições de ensino superior liberdade para organizar e determinar como seriam as avaliações de reconhecimento e validação dos saberes experienciais dos adultos com mais de 23 anos que não houvessem concluído o $12^{\circ}$ ano de escolarização. Isso gerou uma discrepância entre o número de alunos ingressantes no ensino superior público e no ensino superior privado.

\section{Considerações finais}

A história da educação Portuguesa apresentada demonstra que ao longo dos anos houve desinteresse pela educação de adultos, fato que se foi modificando com a nova estrutura política da Europa. A inserção de Portugal na Comunidade Europeia exigiu do país algumas alterações sociais e econômicas a fim de minimizar as diferenças sociais e econômicas dos países que a integram.

Uma das medidas tomadas pelo Governo Português para aumentar o nível de escolarização da população portuguesa foi investir em processos de acesso ao ensino superior de Jovens e Adultos que não tivessem concluído a educação básica. Assim, quando falamos em Educação de Jovens e Adultos, identificamos que uma das decisões tomadas pelo governo Português para inserção desses jovens no ensino Superior foi o Decreto-Lei no 64/2006, que dá a possibilidade de acesso ao ensino superior para aqueles que não concluíram o ensino básico e têm mais de 23 anos.

Ao analisar os dados de acesso ao ensino superior nos concursos para maiores de 23 anos, observamos que a partir de 2006 houve um aumento na porcentagem de alunos neles inscritos, que passou de 20.000, em 2006/2007, para 25.000, em 2007/2008 
O número de inscritos diminuiu no ano letivo 2011/2012 para aproximadamente 16.000 . Segundo os dados nacionais de acesso ao ensino superior, 26\% dos candidatos que se inscreveram nas provas do concurso de maiores de 23 anos não completaram o processo de candidatura.

A partir deste estudo, em consonância com as pesquisas no campo da história da educação, constatamos que tanto homens quanto mulheres que ingressam no ensino superior por meio dos exames especiais possuem interesses específicos para o acesso e permanência na sala de aula, tais como questões relacionadas com as exigências pontuais do mercado de trabalho.

A partir dos dados disponiveis na DGEEC, constata-se que o número de adultos inscritos nas provas especiais de acesso ao ensino superior é consideravelmente superior ao número de adultos que chegam ao final da provas e ingressam em um curso. O que nos leva a questionar se o concurso Maiores de 23 está sendo praticado conforme o disposto na Lei e se realmente está facilitando o acesso dos estudantes adultos não tradicionais no ensino superior.

De acordo com os dados da DGEEC, houve um aumento no número de adultos que não concluíram o $12^{\circ}$ ano de escolarização matriculados no ensino superior, porém, ao analisar a quantidade dos que se inscrevem para as provas para Maiores de 23 anos, julgamos que esse número deveria ser maior.

\section{Referências}

ADÃO, A. Educação de Adultos. In BARROS, A.; MÓNICA, M. F. (coord.). Dicionário de história de Portugal. Porto: Livraria Figueirinhas, vol. VII, 1999, p. 599 - 601.

ALCOFORADO, L. O modelo da competência e os adultos portugueses não qualificados. Revista Portuguesa de Pedagogia. v. 35(1). Coimbra, 2001, 67-83.

ALCOFORADO, L. Competências, cidadania e profissionalidade: limites e desafios para a construção de um modelo português de educação e formação de adultos. Dissertação de Doutoramento (não publicada). Faculdade de Psicologia e de Ciências da Educação, Universidade de Coimbra, 2008.

ALVES, M.; PIRES, A. L. Aprendizagem ao Longo da Vida e ensino superior: novos públicos, novas oportunidades? ANAIS - Unidade de Investigação Educação $e$ Desenvolvimento, 9, 2009, p. 43-54.

AMORIM, J. P.; AZEVEDO, J.; COIMBRA, J. L. E depois do acesso (de "novos públicos" ao ensino superior): a revolução não acabou. In L., Alcoforado et al. (Orgs.), Educação e Formação de Adultos - Políticas, Práticas e Investigação (pp. 211-225). Coimbra: Imprensa da Universidade de Coimbra, 2011. https://doi.org/10.14195/978-989-26-0228-8_18

BRÁS, J. V. et al. A universidade portuguesa: o abrir do fecho de acesso - o caso dos maiores de 23 anos. Revista Lusófona de Educação, 21. Lisboa: Portugal, 2012, p. 163-178.

CANÁRIO, R. Educação de Adultos. Um campo e uma problemática. Lisboa: Educa, 2008.

CARVALHO, R. História do Ensino em Portugal - desde a fundação da Nacionalidade até o fim do Regime de Salazar-Caetano. Lisboa: Fundação Calouste Gulbenkian, 1986. 
CASTRO, A. et al. Políticas educativas em contextos globalizados: a expansão do ensino superior em Portugal e no Brasil. Revista Portuguesa de Pedagogia, 44(1). Coimbra, 2010, p. 37-61. https://doi.org/10.14195/1647-8614_44-1_2

CORREIA, A. M.; MESQUITA, A. Novos Públicos no Ensino Superior - Desafios da Sociedade do Conhecimento. Lisboa: Edições Sílabo, 2006.

FERREIRA, A. G.; SEIXAS, A. M. Dimensões ideológicas em discursos político-educativos governamentais produzidos em Portugal nas duas últimas décadas do século XX. Estudos do Século XX, 6. Coimbra: Centro de Estudos Interdisciplinares do Século XX da Universidade de Coimbra - CEIS20. 2006, p. 255-282.

FERREIRA, J. B. Globalização e ensino superior: a discussão de Bolonha, Perspectiva, 24(1). Florianópolis - Santa Catarina: Editora UFSC, 2006, p. 229-242.

GIL, Antônio Carlos. Como elaborar projetos de pesquisa. 4. ed. São Paulo: Atlas, 2002.

GUIMARÃES, P.; BARROS, R. A nova política pública de educação e formação de adultos em Portugal. Os educadores de adultos numa encruzilhada? Educação \& Sociedade, 36(131). Campinas-SP, 2015, p. 391-406. https://doi.org/10.1590/ES0101-73302015109444

LEITE, C.; RAMOS, K. Políticas do Ensino Superior em Portugal na fase pós-Bolonha: implicações no desenvolvimento do currículo e das exigências ao exercício docente. Revista Lusófona de Educação, 27. Lisboa, 2014, p. 73-89.

LIMA, L. C. A educação de adultos em Portugal (1974-2004). R. Canário e B. Cabrito, Org. Educação e Formação de Adultos. Mutações e Convergências. Lisboa: EDUCA, 2005, p. 31-60.

LUDKE, M; ANDRÉ, M. D. Pesquisa em educação: abordagens qualitativas. São Paulo: EPU, 1986.

MAGALHÃES, A.; AMARAL, A.; TAVARES, O. Equity, access and institutional competition. Tertiary Education And Management, [s. L.], v. 1, n. 15, p. 35-48, 2009. https://doi.org/10.1080/13583880802700040

MELO, A. et al. Uma proposta educativa na participação de todos: documento de estratégia para desenvolvimento da educação de adultos. Lisboa: Ministério da Educação, 1998.

MONTEIRO, A. et al. (2015). Novos públicos do Ensino Superior: abordagem à aprendizagem de estudantes Maiores de 23 anos. Revista Portuguesa de Pedagogia, 49(1). Coimbra, 2015, p. 131-149. https://doi.org/10.14195/1647-8614_49-1_6

MOIO, I. Reconhecimento de Competências no Ensino Superior: uma realidade reconhecida ou a reconhecer? Dissertação de Doutoramento (não publicada). Faculdade de Psicologia e de Ciências da Educação, Universidade de Coimbra, 2017. 
NÓVOA, A. Política de Educação. In BARROS, A.; MÓNICA, M. F. (coord). Dicionário de história de Portugal. Porto: Livraria Figueirinhas, vol. VII, 1999, p. 591.

PIRES, E. Lei de Bases do Sistema Educativo: apresentação e comentários. Lisboa: Edições ASA, 1987.

PIRES, A. L. O reconhecimento da experiência no Ensino Superior. Um estudo de caso nas universidades públicas portuguesas. Comunicação apresentada no XV Colóquio da AFIRSE: Complexidade: um novo paradigma para investigar e intervir em educação, Lisboa, Portugal, fevereiro de 2007.

PIRES, A. L. Reconhecimento e validação das aprendizagens não formais e informais no ensino superior. Problemas e perspectivas. Revista Medi@ções, 1(2). Setúbal - Portugal, 2010, p. 148-161.

PORTUGAL. Portaria n. ${ }^{\circ}$ 854-A/99 de 04 de outubro. Diário da República n. ${ }^{o}$ 232/99 - I Série B. Lisboa: Ministério da Educação, 1999.

PORTUGAL. Assembleia da República. Lei n³/79 de 10 de janeiro - Eliminação do Analfabetismo. Diário da República. No 08 - I Série. Lisboa, 1979, p. 35-36.

PORTUGAL. Regulamento n. ${ }^{\circ}$ 43/2007, de 26 de março. Diário da República $n .^{o} 60-2 .^{a}$ Série. Universidade de Coimbra: Reitoria, 2007.

PORTUGAL. Lei n. ${ }^{\circ}$ 5/73 de 25 de julho. Diário da República $n^{\circ}$ 173/73 - I Série. Lisboa: Ministério da Educação Nacional, 1973.

PORTUGAL. Lei n. ${ }^{\circ}$ 46/86 de 14 de outubro. Diário da República n. ${ }^{\circ}$ 237/86 - I Série A. Lisboa: Ministério da Educação e Cultura, 1986.

PORTUGAL. Lei n. ${ }^{\circ}$ 115/97 de 19 de setembro. Diário da República n. $^{\circ} 217 / 97$ - I Série A. Lisboa: Assembleia da República, 1997.

PORTUGAL. Lei n. ${ }^{\circ}$ 49/05 de 30 de agosto. Diário da República n. $^{\circ}$ 166/05 - I Série A. Lisboa: Ministério da Educação, 2005.

PORTUGAL. Decreto-Lei n. ${ }^{\circ} 402 / 73$ de 11 de agosto. Diário da República $n^{\circ}$ 188/73 - I Série. Lisboa: Ministério da Educação Nacional, 1973.

PORTUGAL. Decreto-Lei n. ${ }^{\circ}$ 393-B/99 de 02 de outubro. Diário da República n. ${ }^{\circ}$ 231/99 - I Série - A. Lisboa: Ministério da Educação, 1999. 
PORTUGAL. Decreto-Lei n. ${ }^{\circ}$ 64/06 de 21 de março. Diário da República $n .^{\circ}$ 57/06 - I Série A. Lisboa: Ministério da Ciência, da Tecnologia e do Ensino Superior, 2006.

PORTUGAL. Decreto-Lei n. ${ }^{\circ}$ 74/06 de 24 de março. Diário da República $n .^{\circ}$ 60/06 - I Série A. Lisboa: Ministério da Ciência, da Tecnologia e do Ensino Superior, 2006.

PORTUGAL. Decreto-Lei n. ${ }^{o} 42 / 05$ de 22 de fevereiro. Diário da República $n .^{\circ}$ 37/05 - I Série A. Lisboa: Ministério da Ciência, Inovação e Ensino Superior, 2005.

SÁ, C.; DIAS D.; TAVARES, O. Tendências recentes no Ensino Superior Português. Livro A3. Agência de Avaliação e Acreditação do Ensino Superior. Lisboa. Publicação Institucional A3, 2013.

SILVA, A. S. Educação de adultos. Educação para o desenvolvimento. Porto: Edições ASA, 1990.

TEODORO, A.; GALEGO, C.; MARQUES, F. Do fim dos eleitos ao Processo de Bolonha: as políticas de educação superior em Portugal (1970-2008). Ensino Em-Revista, 17(2). Uberlândia: EDUFU 2010, p. 657-691. 